\title{
A social network analysis of substance use among immigrant adolescents in six European cities
}

DOI:

10.1016/j.socscimed.2016.09.031

\section{Document Version}

Accepted author manuscript

Link to publication record in Manchester Research Explorer

\section{Citation for published version (APA):}

Lorant, V., Soto Rojas, V., Becares, L., Kinnunen, J., Kuipers, M., Moor, I., Roscillo, G., Alves, J., Grard, A., Rimpelä, A., Federico, B., Richter, M., Perelman, J., \& Kunst, A. (2016). A social network analysis of substance use among immigrant adolescents in six European cities. Social Science and Medicine, 169. https://doi.org/10.1016/j.socscimed.2016.09.031

Published in:

Social Science and Medicine

\section{Citing this paper}

Please note that where the full-text provided on Manchester Research Explorer is the Author Accepted Manuscript or Proof version this may differ from the final Published version. If citing, it is advised that you check and use the publisher's definitive version.

\section{General rights}

Copyright and moral rights for the publications made accessible in the Research Explorer are retained by the authors and/or other copyright owners and it is a condition of accessing publications that users recognise and abide by the legal requirements associated with these rights.

\section{Takedown policy}

If you believe that this document breaches copyright please refer to the University of Manchester's Takedown Procedures [http://man.ac.uk/04Y6Bo] or contact uml.scholarlycommunications@manchester.ac.uk providing relevant details, so we can investigate your claim.

\section{OPEN ACCESS}




\section{Accepted Manuscript}

A social network analysis of substance use among immigrant adolescents in six European cities

Vincent Lorant, Victoria Soto Rojas, Laia Bécares, Jaana M. Kinnunen, Mirte A.G. Kuipers, Irene Moor, Gaetano Roscillo, Joana Alves, Adeline Grard, Arja Rimpelä,

Bruno Federico, Matthias Richter, Julian Perelman, Anton E. Kunst

PII: S0277-9536(16)30538-X

DOI: 10.1016/j.socscimed.2016.09.031

Reference: $\quad$ SSM 10856

To appear in: Social Science \& Medicine

Received Date: 27 June 2016

Revised Date: 13 September 2016

Accepted Date: 21 September 2016

Please cite this article as: Lorant, V., Soto Rojas, V., Bécares, L., Kinnunen, J.M., Kuipers, M.A.G., Moor, I., Roscillo, G., Alves, J., Grard, A., Rimpelä, A., Federico, B., Richter, M., Perelman, J., Kunst, A.E., A social network analysis of substance use among immigrant adolescents in six European cities, Social Science \& Medicine (2016), doi: 10.1016/j.socscimed.2016.09.031.

This is a PDF file of an unedited manuscript that has been accepted for publication. As a service to our customers we are providing this early version of the manuscript. The manuscript will undergo copyediting, typesetting, and review of the resulting proof before it is published in its final form. Please note that during the production process errors may be discovered which could affect the content, and all legal disclaimers that apply to the journal pertain. 


\section{A social network analysis of substance use among immigrant adolescents in six European cities}

Vincent Lorant, PhD $\left(1^{*}\right)$, Victoria Soto Rojas, PhD (1,9), Laia Bécares PhD (2), Jaana M. Kinnunen, MHS (3), Mirte A.G. Kuipers, MSc (4), Irene Moor, MSc (5), Gaetano Roscillo, MSc (6), Joana Alves, $\mathrm{PhD}$ (7), Adeline Grard (1), Arja Rimpelä, PhD (3, 8), Bruno Federico, PhD (6), Matthias Richter, PhD (5), Julian Perelman, PhD (7), Anton E. Kunst, PhD (4)

(1) Institute of Health and Society, Université Catholique de Louvain, Brussels, Belgium

(2) Cathie Marsh Institute for Social Research, University of Manchester, Manchester, UK

(3) School of Health Sciences, University of Tampere, Tampere, Finland

(4) Department of Public Health, Academic Medical Center, University of Amsterdam, Amsterdam, The Netherlands

(5) Institute of Medical Sociology (IMS), Medical Faculty, Martin Luther University Halle-Wittenberg, Halle (Saale), Germany

(6) Department of Human Sciences, Society and Health, University of Cassino and Southern Lazio, Cassino, Italy

(7) Escola Nacional de Saúde Pública and Centro de Investigação em Saúde Pública, Universidade NOVA de Lisboa, Lisbon, Portugal

(8) Department of Adolescent Psychiatry, Pitkäniemi Hospital, Nokia, Tampere University Hospital, Tampere, Finland

(9) Universidad ICESI, PROESA \& Facultad de Ciencias de la Salud, Departamento de Salud Pública, Cali, Colombia.

${ }^{*}$ Corresponding author:

Vincent Lorant

Institute of Health and Society

Université Catholique de Louvain

Clos chapelle aux champs 30 /B1.30.15.05

1200 Bruxelles

Belgium

vincent.lorant@uclouvain.be

Phone: +32 497459869

Fax: +322 7643470 
A social network analysis of substance use among immigrant adolescents in six European

cities 
Abstract

Background. Social integration and the health of adolescents with a migration background is a major concern in multicultural societies. The literature, however, has paid little attention to the wider determinants of their health behaviours, including the composition of their social networks. The aim of this study was to describe the composition of adolescents' social networks according to migration background, and to examine how social networks are associated with substance use. Method. In 2013, the SILNE study surveyed 11,015 secondary-school adolescents in 50 schools in six European cities in Belgium, Finland, Germany, Italy, the Netherlands, and Portugal, using a social network design. Each adolescent nominated up to five of their best and closest friends. Migration status was defined as first-generation migrants, second-generation migrants, and speaking another language at home. We computed two groups of network structural positions, the centrality of individual adolescents in networks, and the homophily of their social ties regarding migration (same-migration). Multilevel logistic regression was used to model the association between network structural position and smoking, alcohol use, and cannabis use. Results. Compared with non-migrant adolescents, adolescents with migration backgrounds had similar relationship patterns. But almost half their social ties were with same-migration-background adolescents; non-migrants had few social ties to migrants. For adolescents with a migration background, a higher proportion of social ties with nonmigrants was associated with increased use of cannabis $(O R=1.07, p=0.03)$ and alcohol $(O R=1.08$, $p<0.01)$, but not with increased smoking $(p=0.60)$. Popular migrant adolescents were at less risk of smoking, alcohol use, and cannabis use than popular non-migrant adolescents. Conclusion. Homophily of social ties by migration background is noticeable in European schools. The tendency of migrant adolescents to have same-migration social ties may isolate them from non-migrant adolescents, but also reduces their risky health behaviours, in particular cannabis and alcohol use. 2 


\section{Keywords:}

Social network analysis, Migrants, Adolescents, Smoking, Cannabis, Alcohol, homophily. 


\section{Introduction}

First- or second-generation migrant adolescents (hereafter, adolescents with a migration background) account for a quarter of all school-age adolescents in Europe (Inchley et al., 2016). It is estimated that the number of immigrants arriving in European countries will increase over the next decade (Brady, 2008).

Several studies have assessed substance use among adolescents with a migration background. The findings of these studies, which have largely focused on the situation of Hispanics, and other migrant groups in the US, are inconclusive (Almeida et al., 2012; Castañeda et al., 2015; Georgiades et al., 2006; Gil et al., 2000; Kim et al., 2002; Lara et al., 2005; Lorenzo-Blanco et al., 2011; Prado et al., 2009; Yu et al., 2003). Some have suggested that adolescents with a migration background are more likely than their counterparts without a migration background to adopt risky health behaviours (such as drinking alcohol and smoking cigarettes or marijuana) (Brindis et al., 1995; Delforterie et al., 2014; Prado et al., 2009; Walsh et al., 2014). However, other studies have found the opposite, reporting that adolescents with a migration background exhibit lower risk of substance use in general (Flavio Francisco Marsiglia et al., 2008; Molcho M et al., 2006), report lower rates of smoking (Georgiades et al., 2006), and are less likely to drink alcohol (Brandom, 2008) than non-immigrant adolescents.

Different factors have been associated with the adoption of substance use behaviours among adolescents with a migration background. Most studies assessed the role of cultural factors such as acculturation or linguistic factors and individual or psychological stressors associated with the migration process (Almeida et al., 2012; Castañeda et al., 2015; Chen et al., 2000; Cheung, 2014; Eitle et al., 2009; Gil et al., 2000; Gordon-Larsen et al., 2003; Lara et al., 2005; Rostila, 2010; Warner et al., 
2010). Yet, as argued elsewhere, research on migration and health may have over-emphasised the role of cultural factors (including, among others, values and beliefs) and it may instead need a better understanding of the role of structural social determinants of health (Castañeda et al., 2015).

One such social determinant of health is the adolescent's social network. It is now well acknowledged that adolescents tend to adopt health behaviours that are similar to their friends' behaviours, and this has been shown in a range of domains such as substance use, nutrition, and sexual activity (Ajilore, 2015; Clark \& Loheac, 2007; Ennett et al., 2006; Kobus, 2003; McGloin et al., 2014; Simons-Morton \& Farhat, 2010; T. W. Valente et al., 2004). Moreover, exposure to substance use is associated with the structural position of an adolescent in the network. Studies suggest that those with more friendships are more likely to smoke or to drink than those with fewer friends (Balsa et al., 2011; Ennett et al., 2006; Fujimoto \& Valente, 2012; Huang et al., 2014; Mundt, 2011; Osgood et al., 2014; Tucker et al., 2011).

However, there has been little research on the role of social networks in the health behaviours of adolescents with a migration background. A particular challenge to such research is to take into account the demographic composition of the social networks. Adolescents' friends are not chosen at random: an adolescent is more likely to befriend other adolescents of the same gender, socioeconomic status, and, relevant to the present study, migration or ethnicity, a pattern known as "homophily" (McPherson et al., 2001; Noel \& Nyhan, 2011; Rivera et al., 2010). Homophily has been defined as "a tendency for friendships to form between those who are alike in some designated respect" (Rivera et al., 2010). For adolescents with a migration background, homophily may be a double-edged sword, i.e. with both positive and adverse consequences. 
On the positive side, homophily can be a source of social support and can help to decrease exposure to prejudice and racial discrimination (Lorenzo-Blanco et al., 2011). It also protects identity, facilitates trust and social interaction, and provides power to resist othering (Hjern et al., 2013). Research in Australia also shows that immigrant adolescents who had peers with a similar migration background reported lower alcohol or tobacco use than their non-immigrant counterparts (Brandom, 2008). Homophily of social relationships in adolescents with a migration background may thus protect them from predominant social norms involving risky behaviours such as smoking, drinking, or drug use (Hernandez et al., 1998; Lara et al., 2005).

On the negative side, homophily may have negative implications for adolescents with a migration background, as it may affect their socio-economic opportunities (Lorant \& Bhopal, 2011) and their social capital. Some studies indicate that adolescents with a migration background in schools with a larger proportion of pupils who are non-migrants are more likely to have relational problems with their peers at school (Derluyn et al., 2008; Murad et al., 2003). Others have shown that homophilous adolescents had poorer social integration, reinforcing the lower social position of migrant groups (Yu et al., 2003), fostering prejudice(Aboud et al., 2003),and, finally, limiting access to health services (McPherson et al., 2001). This may have detrimental consequences for health behaviours as well.

Thus, for adolescents with a migration background, having peers with a migration background may may have an effect that depends on the implications of homophily. Homophily may be protective against risky behaviours, depending on how much the behaviour is associated with prevailing norms (Coleman, 1988; Portes, 1998). By insulating adolescents with migration background, homophily may keep these adolescents away from the prevailing substance use norms, as suggested elsewhere with adults(Rostila, 2010). So far, there have only been a few empirical studies describing social homophily according to migration background and its association with substance use. Some previous 6 


\section{ACCEPTED MANUSCRIPT}

studies suggested that adolescents with a migration background had a substance use pattern which was vulnerable to their peers' substance use(Delforterie et al., 2014; Kim et al., 2002; Walsh et al., 2014). Those studies, however, did not use a social network design, and thus had an indirect appraisal of peers'substance use; those studies, moreover, had a more limited range: they were limited to one migrant or ethnic group, to a national or regional context, and generally analysed only one substance. To our knowledge, there is no social network study describing adolescents' social ties according to migration background and their effect on different health behaviours. This paper aims to fill this gap in two steps. First, we examine the structural position of adolescents in their networks according to their migration background in six European cities. Second, we estimate the association between the structural position of their relationships and their substance use. 


\section{Method}

Data

We used data from the SILNE study: a whole-network study whose detailed design, including ethical review, has been presented elsewhere (Lorant et al., 2015). The survey was administered between January and November of 2013 to adolescents in 50 schools in six European cities of similar population size and income and with employment rates close to the national average. The cities were Namur (Belgium), Tampere (Finland), Hanover (Germany), Latina (Italy), Amersfoort (the Netherlands), and Coimbra (Portugal). In each city, schools were selected from the local register of schools and were approached to participate. Ethical approvals were obtained from national and local organisations. In each school, two grades, corresponding to 14-16 year-olds, were selected. All registered students in these grades were invited to fill in a written questionnaire about their social relationships in school, health behaviours, and demographic and socio-economic characteristics. The participating schools had a combined total of 13,870 registered adolescents in the two grades selected, of whom 11,015 participated, yielding an average participation rate of $79.4 \%$.

\section{Measures}

We used a broad definition of migration background, which included the history of migration (first and second generation) as well as cultural features (language spoken at home) (Bhopal, 2004). Studies have found that first- and second-generation migrants differ in terms of their socialisation process, integration, and health behaviours (Acevedo-Garcia et al., 2010; Almeida et al., 2012). Language is an important driver of social tie formation, for minority groups(Mehra et al., 1998) and for adolescents (Goodreau et al., 2009). Language spoken at home is, moreover, considered as a proxy of ethnicity (Bhopal, 2004) and a proxy for the degree of acculturation (Yu et al., 2003), which 
is an important determinant of health behaviour in general and substance use in particular (Chen et al., 2000; Lara et al., 2005).

Non-immigrant adolescents were defined as native-born adolescents with native-born parents and speaking the local language at home $(n=7,869)$. First-generation migrants were defined as foreignborn adolescents $(n=770)$. Second-generation migrants included adolescents with at least one foreign-born parent $(n=1,589)$. Adolescents who did not speak the local language at home $(n=717)$ were also categorised as adolescents with a migration background. Adolescents with a migration background were defined as those who were either of the first generation, the second generation, or who did not speak the local language at home. Respondents without any report of migrant status or any report of parent's country of birth were excluded ( $n=296)$. The final sample included 10,265 observations.

This study used a name generator registering social ties that are meaningful and instrumental within the school context (Marin \& Hampton, 2007). As explained elsewhere, adolescents (ego) were asked to nominate up to five best friends (alters): "Who are your best and closest friends?" (Lorant et al., 2015). They were told that they could nominate friends enrolled in two grades of their schools corresponding to the 14-16 age group, using a directory that contained the names of all adolescents in those grades.

Adolescent structural position in the network was captured with three groups of network metrics that are useful in describing the size and diversity of a network: centrality, closure, and homophily (Scott, 2000; Thomas W. Valente, 2010; Wasserman \& Faust, 1994). Centrality captures how important an adolescent is in the network and was described with four measures: popularity, social activity, closeness, and isolation. Popularity is the number of incoming nominations (in-degree), 9 
whereas social activity is the number of outgoing nominations (out-degree). Closeness measures how close an adolescent is to all other adolescents and is the ratio of the total number of adolescents in the network to the total distance to all adolescents in it. We also computed the percentage of adolescents receiving no nomination (hereafter, "isolates"). Closure reflects triangulation (propensity of my friends' friends to be my friends) and was measured by the clustering coefficient, which is the density of ties among ego's friends and is computed as the ratio of the number of reported friendship ties among ego's friends to the number of possible ties among ego's friends. The higher the clustering coefficient, the less open the adolescent's network is to other adolescents. Finally, we computed two indicators of homophily across migration groups. First, we computed the percentage of friendship ties with each migration group as a ratio of the total number of ties. Second, as migrant groups are generally a numerical minority in a school, we computed the Coleman homophily index [1,1]. It takes the value of 0 under the assumption of a random network, that is to say, when the distribution of social ties across migration groups reflects the average distribution of each group in the network, a negative value if social ties are heterophilous (greater chance of migrant to nonmigrant ties), and a positive value if social ties are homophilous (greater chance of migrant to migrant social ties or non-migrant to non-migrant social ties) (Bojanowski \& Corten, 2014). The Coleman index was computed for each individual and aggregated according to different migration dimensions: first-generation, second-generation, and speaking another language at home (not dependent on the generation).

\section{Health behaviours}

Our measure of substance use captured three different outcomes: daily smoking, regular alcohol use, and regular cannabis use. We computed a dummy variable of daily smoking when the adolescent reported smoking at least one cigarette per day in the last 30 days before the survey. Regular alcohol use was a dummy variable indicating whether the adolescent reported having a drink of alcohol more 10 
than two or three times a month in the last 12 months. Finally, regular cannabis use was a dummy variable indicating whether the adolescent reported using cannabis or marijuana two or three times a month or more often over the last 12 months.

\section{Socio-demographic covariates}

Migration background is known to be strongly correlated with socio-economic status (SES), in both adults (Lorant et al., 2008) and adolescents (Georgiades et al., 2013; Morgenstern et al., 2013; Murad et al., 2003). The analysis was thus controlled by the Family Affluence Scale (FAS). FAS is based on a set of questions about the material conditions of the household in which adolescents live, including car ownership, adolescent's own bedroom, family holidays, and home computers (Currie et al., 2008). Adolescents were assigned a score ranging from 0 (low SES) to 7 (high SES). An indicator of academic achievement was also added, as it captures future socio-economic opportunities and may confound the relationship between migration and health behaviours (Doku et al., 2010; Flavio Francisco Marsiglia et al., 2008). Self-reported achievement was measured with a question, "which of the following best describe your score over the last year?", whose categories depended on each country's grading system. The values were classified in two groups: low performance $(18 \%$ of the sample) versus medium-high (82\%).

\section{Statistical analysis}

The statistical analyses were performed in four stages. The migration groups and their health behaviours were compared using chi-square or F-test. Then, the network metrics of these groups were compared using F-tests. Third, multilevel logistic regression analyses were performed in order to determine how adolescent substance use was associated with the structural position metrics, controlling for socio-demographics. Two model specifications were estimated for substance use for migrants and non-migrants. Because the schools may be quite different in terms of migration 11 
composition, age, and socio-economic status, etc., we used multilevel logistic regression and included a random intercept for each school. Model 1 includes age, sex, and the social network metrics, while Model 2 also adjusts for other socio-demographic confounders. All analyses were stratified according to adolescent migration status. In the fourth stage, we stratified Model 2 according to migrant status based on two variables that captured normative factors associated with substance use: gender and average school prevalence of substance use. All analyses were conducted with SAS 9.3, using proc iml for the network metrics and proc glimmix for the multilevel logistic regression. 


\section{Results}

\section{Sample and health behaviours}

A quarter of the adolescents had a migration background $(26 \%, n=2850)$, including first-generation adolescents $(7 \%, n=770)$, second-generation $(14 \%, n=1.589)$, and those who did not speak the local language at home $(7 \%, \mathrm{n}=717)$. There were significant socio-demographic differences between nonmigrant and migrant groups: adolescents with a migration background were older, had lower family affluence, and were performing slightly less well at school (Table 1).

[Table 1 here]

A mixed picture was observed for the association between migration background and substance use (Table 1). Smoking was equally common across the different migration background groups, although we found a slightly higher prevalence of daily smoking among first-generation adolescents than among non-migrants ( $17 \%$ versus $14 \%$, Table 1$)$. Compared with adolescents with no migration background, migrants were less likely to have used alcohol over the last month ( $32.4 \%$ vs $36.0 \%$, all $p<0.001)$ and more likely to have ever used cannabis $(18.9 \%$ vs $15.1 \%)$. Adolescents who spoke a non-local language at home reported lower use of alcohol and cannabis than adolescents without a migration background.

\section{Structural position and migration background}

Migrants had slightly lower popularity and social activity than non-migrants (3.2 vs 3.4, Table 2) and were also more frequently isolated than non-migrants $(8.4 \%$ vs $6.2 \%, p<0.01)$. The clustering of friendship ties was high and quite similar among migration groups, but higher for adolescents speaking another language at home than for non-migrants ( $45.3 \%$ vs. $40.7 \%$ ). 13 
[Table 2 here]

Non-migrants were more homophilous than migrants (Table 2): while non-migrants had most of their social ties to non-migrants (79.5\%), the percentage was lower for those speaking another language at home (45.8\% of ties to non-migrants) and for adolescents of the second generation (55.9\%). As indicated by the Coleman indices, non-migrants were moderately homophilous (Coleman index $=$ 0.42 ), whereas migrants were neither homophilous nor heterophilous (Coleman index $=0.00$ ). The diagonal of the Coleman index of the last three rows in Table 2 was negative for all migrant groups, implying that, given the migration composition of their school, these groups were more likely to be heterophilous (more chance of friendship ties outside their own specific migration group). For example, adolescents speaking another non-national language at home (fifth column of Table 2) were heterophilous, as they had more chance of friendship tie to those speaking the national language at home (last row of Table 2 , Coleman $=-0.36$ ).

Figure 1 describes friendship homophily according to migration for each school, with the Coleman index of homophily of migrants on the vertical axis (value $>0$ means homophily) and the percentage of migrants in each school on the horizontal axis. Homophily increases dramatically with the percentage of migrants: the higher the density of migrants in a school, the more homophilous migrant adolescents are. There is also considerable heterogeneity across schools and countries. Most German schools displayed a higher level of homophily according to migration status, suggesting a higher homophily according to migration compared with Portugal and Italy. 
Tables 3 and 4 describe the association between substance use and structural position by migration status. At this stage of the analysis, all migration groups were merged into one group ("with migration background"). Social activity was associated with lower risk of smoking in both groups $(\mathrm{OR}=0.86$ in non-migrants; $\mathrm{OR}=0.87$ in migrants) whereas popularity was associated with a higher risk among non-migrants only. Being isolated was associated with a high risk of smoking among nonmigrants $(\mathrm{OR}=1.63, p=0.01$, table 3 , model 2 ) but not among migrants. Clustering (density of ties among friends) was protective in both groups, but with borderline significance for migrants. Having a higher proportion of ties to non-migrants was not associated with a lower risk of smoking either for adolescents with a migration background or for non-migrant adolescents (Model 2).

[Table 3 here]

Popularity was associated with more frequent use of alcohol in non-migrants, but not in migrants (Table 4). Clustering was protective in both groups and slightly more so among migrants (OR migrants $=0.95$ vs OR non-migrants=0.97). Among adolescents with a migration background, having a higher proportion of friendship ties with non-migrants was associated with a higher risk of regular alcohol use $(\mathrm{OR}=1.08, p=0.02$, Table 4). Having more ties to adolescents with a non-migration background increased the use of cannabis (Table 4, lower panel): for each 10\% increase in the proportion of ties with adolescents with a non-migration background, the risk of having used cannabis in the last month was higher $(\mathrm{OR}=1.07, p=0.03$ ) among adolescents with a migration background (Model 2, lower panel of Table 4).

[Table 4 here] 


\section{ACCEPTED MANUSCRIPT}

Table 5 shows the association of the percentage of ties to non-migrants with alcohol (upper section) and cannabis (lower section) use, according to two stratification variables (sex and the average prevalence of use in the school; school-level average $=33 \%$ for alcohol, and $7 \%$ for cannabis use). Smoking was not retained for this analysis, as it was not associated with the percentage of ties to non-migrants in Table 3. For alcohol, the effect was quite similar across sex or prevalence groups. However, having more non-migrant friendship ties was associated with more alcohol use among girls than among boys, particularly where the average prevalence of alcohol use in the school was low. For cannabis, girls with migration background were again more at risk when they had more friendship ties to non-migrants, but the associations were not statistically significant.

[Table 5 here] 


\section{Discussion}

This paper is among the first to describe the association between substance use and homophily of social ties for adolescents with and without a migration background. The findings show that adolescents with migration backgrounds had similar patterns of social relationships than adolescents without a migration background. Yet, adolescents with a migration background had only half their social ties to non-immigrant adolescents, and that percentage was still lower for those of the firstgeneration and those speaking another non-local language at home. This homophily was driven by school composition: given the migrants composition of their school, adolescents with a migration background were as likely to have friendship ties to non-migrants as to migrants. This homophily of social ties according to migration background is consistent with several studies focusing on separation by race in the US (Moody, 2001) or by ethnicity in Europe (Boda \& Néray, 2015; Smith et al., 2016). A recent study analysing 958 classrooms in Sweden, Germany, England, and the Netherlands also showed that homophily increased (but in a non-linear way) with the proportion of non-natives in the classroom (Smith et al., 2016).

Network structural factors influenced substance use by migrant and non-migrant adolescents in different ways. Clustering and homophily were more protective in relation to cannabis use and alcohol use (but not smoking) among adolescents with a migration background than among adolescents without a migration background. Similarly, being popular put migrant adolescents at less risk of smoking, alcohol use, and cannabis use than adolescents with no migration background. These findings are in line with studies that have examined the concentration of ethnic-minority students in school settings (school ethnic density). Those studies report that higher school ethnic density is associated with improved mental health (Georgiades et al., 2013; Gieling et al., 2010) and reduced substance use (F. F. Marsiglia et al., 2004) among ethnic-minority pupils. Studies of ethnic density among ethnic-minority adults have also shown that people living among a greater proportion of 17 
ethnic-minority residents are less likely to consume alcohol (Bécares et al., 2011). Although studies of ethnic density do not explicitly examine social ties, as we have done in this study, both lines of enquiry suggest that socialising with other migrants or ethnic minorities provides people with a migrant background with increased social cohesion, social support, and decreased exposure to racial discrimination (Bécares et al., 2009). Our findings suggest that, for adolescents with a migration background, clustering and homophily are protective (against cannabis and alcohol), whereas popularity does not affect their substance use, suggesting that cohesion provides health behaviour benefits.

Homophily was, however, protective in relation to the use of cannabis (an illegal substance) and alcohol use (less legitimate in some migrant groups), but not for smoking, which is more common in non-Western countries. This is in line with previous studies, which found that the effect of acculturation is much stronger for alcohol and drug use than for smoking, particularly among women (Lara et al., 2005). This could mean that homophily has some normative content, by discouraging less legitimate behaviours. This is supported by the finding that homophily is slightly more protective for women than for men, a finding consistent with acculturation studies that show that women are more likely to drink when they become acculturated, compared with men (Lara et al., 2005).These results may, moreover, be consistent with the theory of complex contagion, which suggests that homophily affects inequality in relation to behaviour that is more illegitimate (Dimaggio \& Garip, 2011): the more illegitimate a behaviour, the more it relies on strongly-knitted groups to be maintained and learned, as evidenced by the landmark study by Horward Becker (Becker, 1997).

This may also explain why homophily was more protective for girls with a migration background than for boys with a migration background: drinking alcohol may be associated with stronger illegitimacy among migrant girls than among migrant boys, given that most alcohol consumption in adolescents takes place during social events. Indeed, adolescents who spoke another language at home were less 18 
likely to drink alcohol not only than non-migrants but also than migrants of the second generation, possibly because of the stronger perception of drinking as illegitimate in this group, particularly if their religion prohibits drinking alcohol.

Our study was limited in the following ways. First, adolescents with a migration background are a heterogeneous group, reflecting a variety of countries of origin, religions, cultures, and migration histories, each one possibly linked with different risks of unhealthy behaviours. Although our overall percentage of migrants is quite consistent with the recent HBSC survey (Inchley et al., 2016), we could not, for example, distinguish religious and ethnic subgroups that may affect behaviours differently depending on more specific migration experience and cultural norms; "speaking another language at home" was also a crude indicator of acculturation. Moreover, as adolescents from ethnic minority groups have a greater share of their friends outside the school, our full network design may also underrepresent the friendship network of adolescents with a migration background compared with adolescents with a non-migration background (Dubois \& Hirsch, 1990; Witkow \& Fuligni, 2010). The diversity of migration groups across the six countries surveyed, the limited statistical power for specific migrants groups and the social network design obviously influenced our methodological choices and mask these diversities.

Second, our cross-sectional design cannot separate homophily as a result of not being willing to engage in risky behaviours from homophily preventing risky health behaviours, as some migrant groups may hang out with non-migrants because they share the same behaviour preferences. $A$ third potential problem may be different response patterns between migrant and non-migrant adolescents due to a social acceptability bias associated with substance use or to the composition of their in-school versus out-school networks: migrants may be more likely to under-report substance use (Kypri et al., 2004; Steinbauer et al., 1998) and more likely to have more of their friends outside the schools (Witkow \& Fuligni, 2010). We assessed the first risk by computing the number of missing 19 
substance-use items for non-migrants and migrants and testing for difference using a Poisson model: non-migrants had indeed a smaller number of missing items than migrants (mean respectively of 0.02 and $0.07, \mathrm{LR}$ Chi $=127.7, \mathrm{p}<0.01)$. This confirms a higher risk of under-reporting by migrants than by non-migrants.

Despite these limitations, our study indicates, for the first time, that the tendency of migrant adolescents to be part of homogeneous networks may have the mixed effects of isolating them from non-migrant adolescents, but, at the same time, protecting them from some risky health behaviours related to alcohol and cannabis consumption.

Policy implication

This paper highlights the need to better coordinate educational policies and health promotion policies if both social integration and the prevention of substance use are to be achieved in schools, particularly in urban areas. 
References

Aboud, F.E., Mendelson, M.J., \& Purdy, K.T. (2003). Cross-race peer relations and friendship quality. International Journal of Behavioral Development, 27, 165-173.

Acevedo-Garcia, D., Bates, L.M., Osypuk, T.L., \& McArdle, N. (2010). The effect of immigrant generation and duration on self-rated health among US adults 2003-2007. Social Science and Medicine, 71, 1161-1172.

Ajilore, O. (2015). Identifying peer effects using spatial analysis: the role of peers on risky sexual behavior. Review of Economics of the Household, 13, 635-652.

Almeida, J., Johnson, R.M., Matsumoto, A., \& Godette, D.C. (2012). Substance use, generation and time in the United States: The modifying role of gender for immigrant urban adolescents. Social Science \& Medicine, 75, 2069-2075.

Balsa, A.I., Homer, J.F., French, M.T., \& Norton, E.C. (2011). Alcohol use and popularity: Social payoffs from conforming to peers' behavior. Journal of Research on Adolescence, 21, 559-568.

Bécares, L., Nazroo, J., \& Stafford, M. (2009). The buffering effects of ethnic density on experienced racism and health. Health and Place, 15, 670-678.

Bécares, L., Nazroo, J., \& Stafford, M. (2011). The ethnic density effect on alcohol use among ethnic minority people in the UK. Journal of Epidemiology and Community Health, 65, 20-25.

Becker, H.S. (1997). Outsiders : studies in the sociology of deviance. New York ; London: Free Press.

Bhopal, R. (2004). Glossary of terms relating to ethnicity and race: for reflection and debate. J Epidemiol Community Health, 58, 441-445.

Boda, Z., \& Néray, B. (2015). Inter-ethnic friendship and negative ties in secondary school. Social Networks, 43, 57-72.

Bojanowski, M., \& Corten, R. (2014). Measuring segregation in social networks. Social Networks, 39, 14-32.

Brady, H. (2008). EU migration policy : an A-Z. London: Centre for European Reform.

Brandom, P. (2008). The health risk heath behaviours and social connectedness of adolescents in immigrant families: evidence from Australia. International Migration., 46.

Brindis, C., Wolfe, A.L., McCarter, V., Ball, S., \& Starbuck-Morales, S. (1995). The associations between immigrant status and risk-behavior patterns in Latino adolescents. J Adolesc Health, $17,99-105$.

Castañeda, H., Holmes, S.M., Madrigal, D.S., Young, M.E.D., Beyeler, N., \& Quesada, J. (2015). Immigration as a social determinant of health. Annual Review of Public Health pp. 375-392).

Chen, J., Bauman, A., Rissel, C., Tang, K.C., Forero, R., \& Flaherty, B. (2000). Substance use in high school students in New South Wales, Australia, in relation to language spoken at home. Journal of Adolescent Health, 26, 53-63.

Cheung, N.W.T. (2014). Social stress, locality of social ties and mental well-being: The case of rural migrant adolescents in urban China. Health and Place, 27, 142-154.

Clark, A.E., \& Loheac, Y. (2007). "It wasn't me, it was them!" Social influence in risky behavior by adolescents. Journal of Health Economics, 26, 763-784.

Coleman, J.S. (1988). Social Capital in the Creation of Human-Capital. American Journal of Sociology, 94, S95-S120.

Currie, C., Molcho, M., Boyce, W., Holstein, B., Torsheim, T., \& Richter, M. (2008). Researching health inequalities in adolescents: the development of the Health Behaviour in School-Aged Children (HBSC) family affluence scale. Soc Sci Med, 66, 1429-1436. 
Delforterie, M.J., Creemers, H.E., \& Huizink, A.C. (2014). Recent cannabis use among adolescent and young adult immigrants in the Netherlands - The roles of acculturation strategy and linguistic acculturation. Drug and Alcohol Dependence, 136, 79-84.

Derluyn, I., Broekaert, E., \& Schuyten, G. (2008). Emotional and behavioural problems in migrant adolescents in Belgium. European Child \& Adolescent Psychiatry, 17, 54-62.

Dimaggio, P., \& Garip, F. (2011). How network externalities can exacerbate intergroup inequality. American Journal of Sociology, 116, 1887-1933.

Doku, D., Koivusilta, L., Rainio, S., \& Rimpela, A. (2010). Socioeconomic differences in smoking among Finnish adolescents from 1977 to 2007. J Adolesc Health, 47, 479-487.

Dubois, D.L., \& Hirsch, B.J. (1990). School and Neighborhood Friendship Patterns of Blacks and Whites in Early Adolescence. Child Development, 61, 524-536.

Eitle, T.M., Wahl, A.M.G., \& Aranda, E. (2009). Immigrant generation, selective acculturation, and alcohol use among Latina/o adolescents. Social Science Research, 38, 732-742.

Ennett, S.T., Bauman, K.E., Hussong, A., Faris, R., Foshee, V.A., Cai, L., et al. (2006). The peer context of adolescent substance use: Findings from social network analysis. Journal of Research on Adolescence, 16, 159-186.

Fujimoto, K., \& Valente, T.W. (2012). Decomposing the components of friendship and friends' influence on adolescent drinking and smoking. J Adolesc Health, 51, 136-143.

Georgiades, K., Boyle, M.H., Duku, E., \& Racine, Y. (2006). Tobacco use among immigrant and nonimmigrant adolescents: Individual and family level influences. Journal of Adolescent Health, 38, 443.e441-443.e447.

Georgiades, K., Boyle, M.H., \& Fife, K.A. (2013). Emotional and Behavioral Problems Among Adolescent Students: The Role of Immigrant, Racial/Ethnic Congruence and Belongingness in Schools. Journal of Youth and Adolescence, 42, 1473-1492.

Gieling, M., Vollebergh, W., \& Van Dorsselaer, S. (2010). Ethnic density in school classes and adolescent mental health. Social Psychiatry and Psychiatric Epidemiology, 45, 639-646.

Gil, A.G., Wagner, E.F., \& Vega, W.A. (2000). Acculturation familism, and alcohol use among Latino adolescent males: Longitudinal relations. Journal of Community Psychology, 28, 443-458.

Goodreau, S.M., Kitts, J.A., \& Morris, M. (2009). Birds of a feather, or friend of a friend? Using exponential random graph models to investigate adolescent social networks. Demography, 46, 103-125.

Gordon-Larsen, P., Harris, K.M., Ward, D.S., \& Popkin, B.M. (2003). Acculturation and overweightrelated behaviors among Hispanic immigrants to the US: the national longitudinal study of adolescent health. Social Science \& Medicine, 57, 2023-2034.

Hernandez, D.J., Charney, E., \& National Research Council (U.S.). Committee on the Health and Adjustment of Immigrant Children and Families. (1998). From generation to generation : the health and well-being of children in immigrant families. Washington, DC: National Academy Press.

Hjern, A., Rajmil, L., Bergström, M., Berlin, M., Gustafsson, P.A., \& Modin, B. (2013). Migrant density and well-being - A national school survey of 15-year-olds in Sweden. European Journal of Public Health, 23, 823-828.

Huang, G.C., Soto, D., Fujimoto, K., \& Valente, T.W. (2014). The interplay of friendship networks and social networking sites: longitudinal analysis of selection and influence effects on adolescent smoking and alcohol use. Am J Public Health, 104, e51-59.

Inchley, J., Currie, D., Taryn Young, Samdal, O., Torsheim, T., Augustson, L., et al. (2016). Growing up unequal:gender and socioeconomic differences in young people's health and well-being: Health behaviour in school-aged children (HBSC) study: international report from the 2013/2014 survey. HEALTH POLICY FOR CHILDREN AND ADOLESCENTS, NO. 7 (p. 294). Copenhagen: WHO Regional Office for Europe. 
Kim, I.J., Zane, N.W.S., \& Hong, S. (2002). Protective factor against substance use among Asian American youth: A test of the peer cluster theory. Journal of Community Psychology, 30, 565584.

Kobus, K. (2003). Peers and adolescent smoking. Addiction, 98, 37-55.

Kypri, K., Stephenson, S., \& Langley, J. (2004). Assessment of Nonresponse Bias in an Internet Survey of Alcohol Use. Alcoholism: Clinical and Experimental Research, 28, 630-634.

Lara, M., Gamboa, C., Kahramanian, M.I., Morales, L.S., \& Bautista, D.E.H. (2005). Acculturation and latino health in the United States: A review of the literature and its sociopolitical context. Annual Review of Public Health, 26, 367-397.

Lorant, V., \& Bhopal, R.S. (2011). Ethnicity, socio-economic status and health research: insights from and implications of Charles Tilly's theory of Durable Inequality. J Epidemiol Community Health, 65, 671-675.

Lorant, V., Soto, V.E., Alves, J., Federico, B., Kinnunen, J., Kuipers, M., et al. (2015). Smoking in schoolaged adolescents: design of a social network survey in six European countries. BMC Res Notes, 8, 91.

Lorant, V., Van Oyen, H., \& Thomas, I. (2008). Contextual factors and immigrants' health status: double jeopardy. Health Place, 14, 678-692.

Lorenzo-Blanco, E.I., Unger, J.B., Ritt-Olson, A., Soto, D., \& Baezconde-Garbanati, L. (2011). Acculturation, Gender, Depression, and Cigarette Smoking Among US Hispanic Youth: The Mediating Role of Perceived Discrimination. Journal of Youth and Adolescence, 40, 15191533.

Marin, A., \& Hampton, K.N. (2007). Simplifying the personal network name generator: Alternatives to traditional multiple and single name generators. Field Methods, 19, 163-193.

Marsiglia, F.F., Kulis, S., Hecht, M.L., \& Sills, S. (2004). Ethnicity and ethnic identity as predictors of drug norms and drug use among preadolescents in the US Southwest. Substance Use and Misuse, 39, 1061-1094.

Marsiglia, F.F., Kulis, S., Luengo, M.A., Nieri, T., \& Villar, P. (2008). Immigrant advantage? Substance use among Latin American immigrant and native-born youth in Spain. Ethnicity \& Health, 13, 149-170.

McGloin, J.M., Sullivan, C.J., \& Thomas, K.J. (2014). Peer Influence and Context: The Interdependence of Friendship Groups, Schoolmates and Network Density in Predicting Substance Use. Journal of Youth and Adolescence, 43, 1436-1452.

McPherson, M., Smith-Lovin, L., \& Cook, J.M. (2001). Birds of a feather: Homophily in social networks. pp. 415-444).

Mehra, A., Kilduff, M., \& Brass, D.J. (1998). At the margins: A distinctiveness approach to the social identity and social networks of underrepresented groups. Academy of Management Journal, 41, 441-452.

Molcho M, Cristini F, Gabhainn N, Santinello M, Moreno C, Gaspar de Matos M, et al. (2006). Health and well-being among child immigrants in Europe. Eurohealth, 16, 20-23.

Moody, J. (2001). Race, school integration, and friendship segregation in America. American Journal of Sociology, 107, 679-716.

Morgenstern, M., Sargent, J.D., Engels, R.C.M.E., Florek, E., \& Hanewinkel, R. (2013). Smoking in European adolescents: Relation between media influences, family affluence, and migration background. Addictive Behaviors, 38, 2589-2595.

Mundt, M.P. (2011). The impact of peer social networks on adolescent alcohol use initiation. Academic Pediatrics, 11, 414-421.

Murad, S.D., Joung, I.M.A., van Lenthe, F.J., Bengi-Arslan, L., \& Crijnen, A.A.M. (2003). Predictors of self-reported problem behaviours in Turkish immigrant and Dutch adolescents in the Netherlands. Journal of Child Psychology and Psychiatry and Allied Disciplines, 44, 412-423. 
Noel, H., \& Nyhan, B. (2011). The 'unfriending' problem: The consequences of homophily in friendship retention for causal estimates of social influence. Social Networks, 33, 211-218.

Osgood, D.W., Feinberg, M.E., Wallace, L.N., \& Moody, J. (2014). Friendship group position and substance use. Addictive Behaviors, 39, 923-933.

Portes, A. (1998). Social Capital: Its origins and applications in modern sociology. Annual Review of Sociology, 24, 1-24.

Prado, G., Huang, S., Schwartz, S.J., Maldonado-Molina, M.M., Bandiera, F.C., de la Rosa, M., et al. (2009). What Accounts for Differences in Substance Use Among US-Born and Immigrant Hispanic Adolescents?: Results from a Longitudinal Prospective Cohort Study. Journal of Adolescent Health, 45, 118-125.

Rivera, M.T., Soderstrom, S.B., \& Uzzi, B. (2010). Dynamics of dyads in social networks: Assortative, relational, and proximity mechanisms. Annual Review of Sociology pp. 91-115).

Rostila, M. (2010). Birds of a feather flock together - and fall ill? Migrant homophily and health in Sweden. Sociology of Health and IIIness, 32, 382-399.

Scott, J. (2000). Social network analysis: a handbook. London: SAGE Publications.

Simons-Morton, B.G., \& Farhat, T. (2010). Recent Findings on Peer Group Influences on Adolescent Smoking. Journal of Primary Prevention, 31, 191-208.

Smith, S., McFarland, D.A., Tubergen, F.V., \& Maas, I. (2016). Ethnic composition and friendship segregation: Differential effects for adolescent natives and immigrants. American Journal of Sociology, 121, 1223-1272.

Steinbauer, J.R., Cantor, S.B., Holzer lii, C.E., \& Volk, R.J. (1998). Ethnic and sex bias in primary care screening tests for alcohol use disorders. Annals of Internal Medicine, 129, 353-362.

Tucker, J.S., Green Jr, H.D., Zhou, A.J., Miles, J.N.V., Shih, R.A., \& D’Amico, E.J. (2011). Substance use among middle school students: Associations with self-rated and peer-nominated popularity. Journal of Adolescence, 34, 513-519.

Valente, T.W. (2010). Social networks and health models, methods, and applications. Oxford: Oxford University Press.

Valente, T.W., Gallaher, P., \& Mouttapa, M. (2004). Using social networks to understand and prevent substance use: A transdisciplinary perspective. Substance Use and Misuse, 39, 1685-1712.

Walsh, S.D., Djalovski, A., Boniel-Nissim, M., \& Harel-Fisch, Y. (2014). Parental, peer and school experiences as predictors of alcohol drinking among first and second generation immigrant adolescents in Israel. Drug and Alcohol Dependence, 138, 39-47.

Warner, K., Hamza, M., Oliver-Smith, A., Renaud, F., \& Julca, A. (2010). Climate change, environmental degradation and migration. Natural Hazards, 55, 689-715.

Wasserman, S., \& Faust, K. (1994). Social network analysis : methods and applications. Cambridge: Cambridge University Press.

Witkow, M.R., \& Fuligni, A.J. (2010). In-school versus out-of-school friendships and academic achievement among an ethnically diverse sample of adolescents. Journal of Research on Adolescence, 20, 631-650.

Yu, S.M., Huang, Z.J., Schwalberg, R.H., Overpeck, M., \& Kogan, M.D. (2003). Acculturation and the health and well-being of U.S. immigrant adolescents. J Adolesc Health, 33, 479-488. 


\section{Competing interests:}

The authors report no conflict of interest in relation to this study.

\section{Authors' contributions:}

VL designed and supervised the study. VL and VS conceived the research questions, performed the data analysis, and drafted the manuscript. JK, AR, MK, IM, MR, GR, BF, JA, and JP administered the survey in each European city. AK assisted in the study's conception and contributed to its development. All authors read, contributed to, revised, and approved the final manuscript.

\section{Acknowledgements:}

This study is part of the project "Tackling socio-economic inequalities in smoking: learning from natural experiments by time trend analyses and cross-national comparisons" - SILNE, which is funded by the European Commission, Directorate General for Research and Innovation, under FP7 Health 2011 program, with grant agreement No. 278273.

VL has benefited from a COST- ACTION IS1103 grant while visiting the Centre on Dynamics and Ethnicity (CODE), University of Manchester, in 2015-16. VL is grateful to the CoDE group for its members' support and valuable suggestions in drafting and revising this paper. 
Table 1. Socio-economic covariates and health behaviour by migration-background groups: mean and F-test, SILNE international study of adolescents' health behaviours, 2013

\begin{tabular}{|c|c|c|c|c|c|c|c|}
\hline Covariate & $\begin{array}{c}\text { Non- } \\
\text { migrants } \\
(\mathrm{n}=8,165)\end{array}$ & $\begin{array}{c}\text { All } \\
\text { Migrants } \\
(\mathrm{n}=2,850)\end{array}$ & $\begin{array}{c}\text { 1st- } \\
\text { Generation } \\
(n=770)\end{array}$ & $\begin{array}{c}\text { 2nd- } \\
\text { Generation } \\
(\mathrm{n}=1,589)\end{array}$ & $\begin{array}{c}\text { Other } \\
\text { language at } \\
\text { home } \\
(\mathrm{n}=717)\end{array}$ & $\begin{array}{l}\text { F or } \chi^{2} \\
\text { Test }(1)\end{array}$ & \\
\hline \multicolumn{8}{|l|}{ Socio-demographics: } \\
\hline Female $(\%)$ & 52.1 & 50.0 & 53.0 & 49.7 & 42.8 & 4.1 & 0.04 \\
\hline Age (y.) & 15.2 & 15.4 & 15.8 & 15.2 & 15.5 & 93.9 & $<.001$ \\
\hline FAS score $(0-7)$ & 5.6 & 5.1 & 4.8 & 5.3 & 4.4 & 287.2 & $<.001$ \\
\hline $\begin{array}{l}\text { Low academic performance } \\
(\%)\end{array}$ & 16.8 & 19.9 & 20.4 & 20.0 & 17.6 & 13.5 & $<.001$ \\
\hline \multicolumn{8}{|l|}{ Health behaviour: } \\
\hline Daily smoker (\%) & 14.3 & 15.2 & 17.1 & 13.6 & 15.6 & 1.1 & 0.29 \\
\hline $\begin{array}{l}\text { Use of alcohol in the last } \\
\text { month }(\%)\end{array}$ & 36.0 & 32.4 & 28.8 & 32.1 & 25.4 & 11.9 & $<.001$ \\
\hline Use of cannabis last month (\%) & 6.4 & 9.1 & 10.2 & 8.8 & 7.6 & 23.2 & $<.001$ \\
\hline
\end{tabular}

(1)Comparing all migrant groups to non-migrants; F-test for age and FAS (family affluence scale) score and Chi-Square otherwise. 
Table 2. Friendship social ties by migration-background group, Structural position indicators, SILNE international study of adolescents' health behaviours, 2013

\begin{tabular}{|c|c|c|c|c|c|c|c|}
\hline & $\begin{array}{l}\text { Non- } \\
\text { migrants }\end{array}$ & $\begin{array}{l}\text { All } \\
\text { migrants }\end{array}$ & $\begin{array}{l}\text { 1st- } \\
\text { Generation }\end{array}$ & $\begin{array}{l}\text { 2nd- } \\
\text { Generation }\end{array}$ & $\begin{array}{l}\text { Other } \\
\text { language at } \\
\text { home }\end{array}$ & $\begin{array}{l}\text { F-test } \\
(\&)\end{array}$ & $\begin{array}{l}\mathrm{P} \\
\text { value }\end{array}$ \\
\hline \multicolumn{8}{|l|}{ Centrality and closure: } \\
\hline Isolate $(\%)(\S)$ & 6.2 & 8.4 & 8.8 & 7.4 & 9.8 & 15.9 & $<.01$ \\
\hline Closeness (degree) $(\S)$ & 11.3 & 10.8 & 10.8 & 10.7 & 10.9 & 12.6 & $<.01$ \\
\hline Popularity (nber of in-degree) $(\S)$ & 3.4 & 3.17 & 3.0 & 3.2 & 3.0 & 31.1 & $<.01$ \\
\hline \multicolumn{8}{|l|}{ Social activity (nber of out-degree) } \\
\hline$(\S)$ & 3.4 & 3.18 & 3.1 & 3.2 & 3.0 & 49.9 & $<.01$ \\
\hline Clustering $(\%)(\S)$ & 40.7 & 41.5 & 42.1 & 42.2 & 45.3 & 0.4 & 0.54 \\
\hline \multicolumn{8}{|l|}{ Homophily measures: } \\
\hline Tie to non-migrants $(\%)$ & 79.5 & 55.9 & 49.9 & 55.9 & 45.8 & 1028 & $<.01$ \\
\hline Tie to 1 st-generation $(\%)$ & 4.1 & 12.2 & 22.4 & 9.1 & 15.8 & 451.4 & $<.01$ \\
\hline Tie to $2^{\text {nd }}$-generation $(\%)$ & 12.8 & 27.5 & 23.7 & 31.0 & 34.7 & 494.8 & $<.01$ \\
\hline Tie to other language $(\%)$ & 3.9 & 12.5 & 14.2 & 12.9 & 22.5 & 417.8 & $<.01$ \\
\hline Coleman non-migrant $(-1,1)(\mathbb{I I})$ & 0.42 & 0.00 & 0.14 & -0.01 & 0.23 & 1102 & $<.01$ \\
\hline Coleman $1^{\text {st }}$-generation $(-1,1)$ & 0.81 & 0.42 & -0.36 & 0.67 & 0.31 & 1060 & $<.01$ \\
\hline Coleman $2^{\text {nd }}$-generation $(-1,1)$ & 0.57 & 0.02 & 0.36 & -0.21 & 0.18 & 1591 & $<.01$ \\
\hline Coleman other language $(-1,1)$ & 0.80 & 0.47 & 0.37 & 0.47 & -0.36 & 624.2 & $<.01$ \\
\hline
\end{tabular}

(\&) F-test comparing the first and second groups.

(II) Coleman index ranges from -1 for perfect heterophily (all ties to the other group) and 1 for perfect homophily (all ties to own group) on migration background, with 0 corresponding to a distribution of social ties equivalent to a random network.

(§) Isolates are those having a popularity of 0 , closeness is the average distance to all adolescents, popularity is the number of incoming nominations, social activity is the number of outgoing nominations, clustering is the density of friendship ties among ego' friends. 
Table 3. Structural position covariates of daily smoking by migration background group, odds ratio of the logistic regression, SILNE international study of adolescents' health behaviour, 2013.

\begin{tabular}{|c|c|c|c|c|c|c|c|c|c|c|c|c|}
\hline \multirow[b]{2}{*}{ Covariate } & \multicolumn{6}{|c|}{ Non-migrants } & \multicolumn{6}{|c|}{ With migration background } \\
\hline & OR-M1 $\S$ & std & & OR-M2 $§$ & std & & OR-M1 $§$ & std & & OR-M2 & std & \\
\hline Isolate $(\mathrm{ref}=$ no $)$ & 1.70 & 0.19 & $<.01$ & 1.63 & 0.19 & 0.01 & 1.38 & 0.28 & 0.26 & 1.40 & 0.29 & 0.23 \\
\hline Social activity (nber out- degree) & 0.86 & 0.04 & $<.01$ & 0.86 & 0.04 & $<.01$ & 0.87 & 0.07 & 0.03 & 0.87 & 0.07 & 0.04 \\
\hline Popularity (nber in- degree) & 1.10 & 0.02 & $<.01$ & 1.10 & 0.02 & $<.01$ & 1.01 & 0.04 & 0.78 & 1.02 & 0.04 & 0.58 \\
\hline Closeness (distance) & 1.02 & 0.01 & 0.16 & 1.02 & 0.01 & 0.16 & 1.04 & 0.02 & 0.07 & 1.04 & 0.02 & 0.06 \\
\hline Clustering (10\%) & 0.96 & 0.01 & $<.01$ & 0.96 & 0.01 & $<.01$ & 0.96 & 0.02 & 0.09 & 0.96 & 0.02 & 0.07 \\
\hline Ties to non-migrants $(10 \%)(\mathbb{I})$ & 0.97 & 0.02 & 0.08 & 0.97 & 0.02 & 0.13 & 1.01 & 0.02 & 0.73 & 1.01 & 0.02 & 0.60 \\
\hline High academic performance (ref=low) & & & & 0.49 & 0.10 & $<.01$ & & & & 0.52 & 0.15 & $<.01$ \\
\hline School covariance component mean (std) & 0.54 & 0.15 & & 0.54 & 0.15 & & 0.30 & 0.13 & & 0.27 & 0.13 & \\
\hline
\end{tabular}

(§) Model 1 is controlled for all variables in the table, plus age (y), sex, and a covariance component; Model 2 is additionally controlled for family affluence and academic performance; (II) Percentage of ties to non-migrants as the ratio of the number of ties to all alters (migrants or non-migrants). 
Table 4. Structural position covariates of alcohol and cannabis use in the last month, by migration-background group, odds ratio of the logistic regression, SILNE international study of adolescents' health behaviour, 2013.

\begin{tabular}{|c|c|c|c|c|c|c|c|c|c|c|c|c|}
\hline \multirow[b]{2}{*}{ Covariate } & \multicolumn{6}{|c|}{ Non-migrants } & \multicolumn{6}{|c|}{ With migration background } \\
\hline & OR-M1 $§$ & std & & OR-M2 § & std & & OR-M1 & std & & OR-M2 & std & \\
\hline \multicolumn{13}{|l|}{ Alcohol over the last month: } \\
\hline Isolate $(\mathrm{ref}=\mathrm{no})$ & 1.21 & 0.15 & 0.19 & 1.20 & 0.15 & 0.21 & 1.17 & 0.24 & 0.52 & 1.20 & 0.24 & 0.45 \\
\hline Social activity (nber out- degree) & 0.98 & 0.03 & 0.43 & 0.98 & 0.03 & 0.45 & 0.94 & 0.05 & 0.25 & 0.94 & 0.05 & 0.20 \\
\hline Popularity (nber in- degree) & 1.09 & 0.02 & $<.01$ & 1.08 & 0.02 & $<.01$ & 1.05 & 0.03 & 0.08 & 1.05 & 0.03 & 0.11 \\
\hline Closeness (distance) & 1.00 & 0.01 & 0.95 & 1.00 & 0.01 & 0.90 & 1.02 & 0.02 & 0.22 & 1.02 & 0.02 & 0.22 \\
\hline Clustering (10\%) & 0.97 & 0.01 & $<.01$ & 0.97 & 0.01 & $<.01$ & 0.95 & 0.02 & $<.01$ & 0.95 & 0.02 & $<.01$ \\
\hline Ties to non-migrants $(10 \%, \mathbb{T})$ & 1.00 & 0.01 & 0.71 & 1.00 & 0.01 & 0.78 & 1.09 & 0.02 & $<.01$ & 1.08 & 0.02 & $<.01$ \\
\hline High academic performance (ref=low) & & & & 0.75 & 0.08 & $<.01$ & & & & 0.65 & 0.13 & $<.01$ \\
\hline School covariance component mean (std) & 0.30 & 0 . & & 0.33 & 0.09 & & 0.17 & 0.07 & & 0.18 & 0.07 & \\
\hline \multicolumn{13}{|l|}{ Cannabis over the last month: } \\
\hline Isolate $(\mathrm{ref}=\mathrm{no})$ & 2.13 & 0.26 & $<.01$ & 2.10 & 0.26 & $<.01$ & 1.09 & 0.38 & 0.82 & 1.09 & 0.39 & 0.83 \\
\hline Social activity (nber out- degree) & 0.85 & 0.06 & $<.01$ & 0.85 & 0.06 & $<.01$ & 0.90 & 0.09 & 0.22 & 0.90 & 0.09 & 0.23 \\
\hline Popularity (nber in- degree) & 1.14 & 0.03 & $<.01$ & 1.14 & 0.03 & $<.01$ & 1.01 & 0.05 & 0.78 & 1.03 & 0.05 & 0.60 \\
\hline Closeness (distance) & 1.06 & 0.02 & $<.01$ & 1.05 & 0.02 & $<.01$ & 1.02 & 0.03 & 0.40 & 1.03 & 0.03 & 0.37 \\
\hline Clustering (10\%) & 0.99 & 0.02 & 0.57 & 0.99 & 0.02 & 0.60 & 0.92 & 0.03 & $<.01$ & 0.92 & 0.03 & $<.01$ \\
\hline Ties to non-migrants $(10 \%)(\mathbb{I})$ & 0.95 & 0.02 & 0.06 & 0.96 & 0.02 & 0.08 & 1.06 & 0.03 & 0.05 & 1.07 & 0.03 & 0.03 \\
\hline Lower academic performance (ref=low) & & & & 0.64 & 0.14 & $<.01$ & & & & 0.61 & 0.20 & 0.02 \\
\hline
\end{tabular}




\begin{tabular}{|c|c|c|c|c|c|c|}
\hline \multirow[b]{2}{*}{ Covariate } & \multicolumn{4}{|c|}{ Non-migrants } & \multicolumn{2}{|c|}{ With migration background } \\
\hline & OR-M1 & std & OR-M2 $\$$ & std & OR-M1 $§$ std & OR-M2 $\S$ std \\
\hline School covariance component mean (std & 0.84 & 0.25 & 0.87 & 0.26 & $0.28 \quad 0.15$ & 0.310 .16 \\
\hline
\end{tabular}

(§) Model 1 is controlled for all variables in the table, plus age (y), sex, and a covariance component; Model 2 is additionally controlled for family affluence and academic performance; (I) Percentage of ties to non-migrants as the ratio of the number of ties to all alters (migrants or non-migrants). 
Table 5. Effect of heterophily of friendship ties among migrant adolescents, odds ratio of the multilevel logistic regression stratified by average consumption and sex: SILNE international study of adolescents' health behaviour, 2013

\begin{tabular}{|c|c|c|c|c|c|c|}
\hline \multirow[b]{2}{*}{ School prevalence } & \multicolumn{3}{|l|}{ Boys } & \multicolumn{3}{|c|}{ Girls } \\
\hline & $\begin{array}{c}\text { Odds ratio } \\
\text { of the } \% \text { tie with non- } \\
\text { migrants }(\S)\end{array}$ & Std & $P$ value & $\begin{array}{c}\text { Odds ratio } \\
\text { of the \% tie with non- } \\
\text { migrants }(\S)\end{array}$ & Std & $P$ value \\
\hline Alcohol in the last month $<33 \%$ & 1.05 & 0.04 & 0.28 & 1.13 & 0.04 & $<.01$ \\
\hline Alcohol in the last month $>=33 \%$ & 1.06 & 0.03 & 0.05 & 1.09 & 0.03 & 0.01 \\
\hline Cannabis in the last month $<7 \%$ & 0.99 & 0.06 & 0.79 & 1.41 & 0.18 & 0.31 \\
\hline Cannabis in the last month $>=7 \%$ & 1.09 & 0.05 & 0.07 & 1.05 & 0.06 & 0.55 \\
\hline
\end{tabular}

(§) OR from the multilevel logistic regression for migrants only, controlled for FAS and school performance and the other structural indicators of Table 4. 


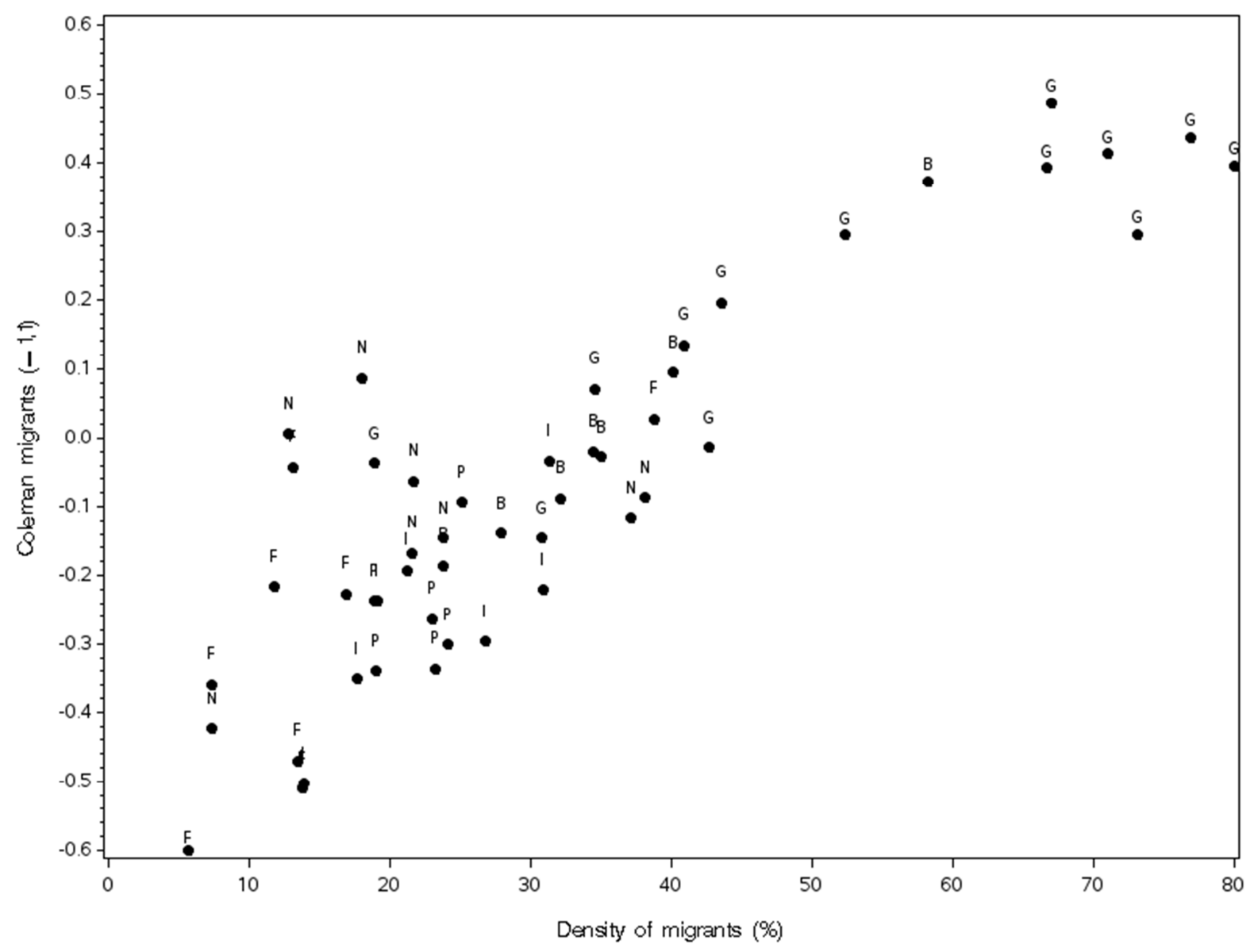

Figure 1. Coleman index of homophily for migrants $(\mathrm{Y})$ and density of migrants (\%) $(\mathrm{X})$, per school.

Legend: each dot represents a school and its location ( $B=$ Belgium, $F=$ Finland, $G=$ Germany, $I=I t a l y$, $\mathrm{N}=$ Netherlands, $\mathrm{P}=$ Portugal). 


\section{Research Highlights:}

- Little is known about the role of social ties in migrant adolescent substance use.

- The pattern of social ties is similar between migrants and non-migrants.

- Most of the social ties of migrant adolescents are with other migrants (homophily).

- Homophily is associated with lower alcohol and cannabis use among migrants. 